\title{
中心区的混合功能与城市尺度构建关系 新加坡滨海湾区模式的启示
}

\author{
Relationship Between Mixed-use and Urban Elements Size in City Central District: \\ The Enlightenment of Singapore Marina Bay Mode
}

陈楠 陈可石 方丹青

Chen Nan, Chen Keshi, Fang Danqing

\begin{abstract}
摘要: 本文针对新加坡滨海湾区多年的建设发展, 探讨了 滨海湾区总体结构、亚区单元、功能混合模式以及城市元 素尺度之间的相互关系, 最后总结滨海湾区城市设计模式 对城市多样性产生的作用, 并探讨了中国未来中心区的发 展建设模式。
\end{abstract}

Abstract: Based on the construction and development of Singapore Marina Bay over years, the paper discusses the relationship between city structure, subzone, mixed-use and urban element size, and summarizes the empirical urban design mode of Marina Bay which can be considered as the foundation of the city diversity. Finally, the paper provides some advice for the development model of urban center area in China.

关键词: 城市多样性; 亚区; 功能混合; 城市元素尺度 Keywords: City Diversity; Subzone; Mixed-use; Urban Elements Size
作者: 陈楠 (通信作者), 北京大学城市规划与设计学院人文 地理学 (城市设计) 博士研究生。44554683@qq.com 陈可石, 北京大学城市规划与设计学院, 教授, 博士 生导师; 北京大学中国城市设计研究中心主任 方丹青, 北京大学城市规划与设计学院人文地理学 (城 市设计）博士研究生
近年来，可持续城市的“多样性”构建已成为城市中心区热衷探 讨的话题, 功能混合与城市的紧凑性也被认为是提高城市多样性的重 要手段。虽然最近 10 年中关于功能混合与形态的研究快速增长, 但在 实际设计中随之而来的各种问题依旧让规划们者捉襟见肘 : 功能如何 混合? 功能混合如何与具体空间模式结合? 基于功能混合的城市系统 如何设计? 这些问题都有待于在实际的城市设计中深人探讨并予之应 用。由于对混合功能与形态关系缺乏深人的认知, 国内许多城市中心 区在实践中最终还是走了 “现代主义 CBD” 的老路一一冰冷的大型建 筑与街道、缺乏活力的中心、失衡的职住关系……而政府在建设后期 想要增加复合功能, 却发现在现有的城市结构下举步维艰。面对新的 城镇化浪潮, 中国未来仍有许多城市中心区等待新建与更新, 因此, 进一步认识混合功能与空间形态之间的模式关系对我国未来的中心区 建设具有重要意义。

新加坡滨海湾区（Marina Bay）从李光耀时期发展至今，已逐渐 被认定为富有多样活力的世界级城市地区, 作为新加坡 “田园城市” 目标的重要体现 ${ }^{[1,2]}$, 其优质的城市空间与多样功能的混合是本文探讨 的重点。本文尝试从城市设计的功能与形态层面对新加坡中心区模式 展开一次研究性解读, 通过对新加坡滨海湾区数十年建设经验的总结, 重新审视我国中心城区中的混合功能与空间结合的模式问题，并探讨 一个充满活力和吸引力的城市中心区在混合功能与空间上应该遵循的 基本策略。

\section{1 滨海湾区概况与研究范围选择}

滨海湾区位于新加坡南端（图 1), 是新加坡的经济文化中心。滨 海湾区的前身是新加坡的 CBD一一莱佛士坊（Raffles Place）以及周边 的历史文化区域, 伴随 1996 年与 2003 年两次 “新都心” 计划的开展, 政府填海造城, 滨海湾逐渐由一个历史中心城区转变成为本土服务的 “生活、工作与休闲娱乐相结合的新城市核心区” ${ }^{[3]}$, 随后又逐渐升级 为全球性的“24 小时全球商业、生活、工作与娱乐中心” ${ }^{[3-5]}$ 。作为新 加坡国际化城市的代表, 滨海湾区良好的环境、丰富的业态以及便捷 
的设施构建了一个功能与形态良好结合的城市设计系统, 这 样的系统是滨海湾能够持续地为新加坡的城市发展提供新的 机遇、吸引新的投资和游客以及培育新的本土社群的关键物 质基础 ${ }^{[6,7]}$, 也是本文重点讨论的对象。

本文研究的滨海湾区范围划定主要参考了新加坡国土 单元规划中的 “中心地带” (Central Area) 以及 “亚区”

(Subzone) 的划定。新加坡政府公布的中心地带包含了大 面积的居住区邻里单元, 本文依据研究内容在中心地带范围 与亚区范围的基础上, 参照滨海湾规划、新加坡中心功能区 域做了研究范围界定, 总体规模为 $4.94 \mathrm{~km}^{2}$ (图 1)。

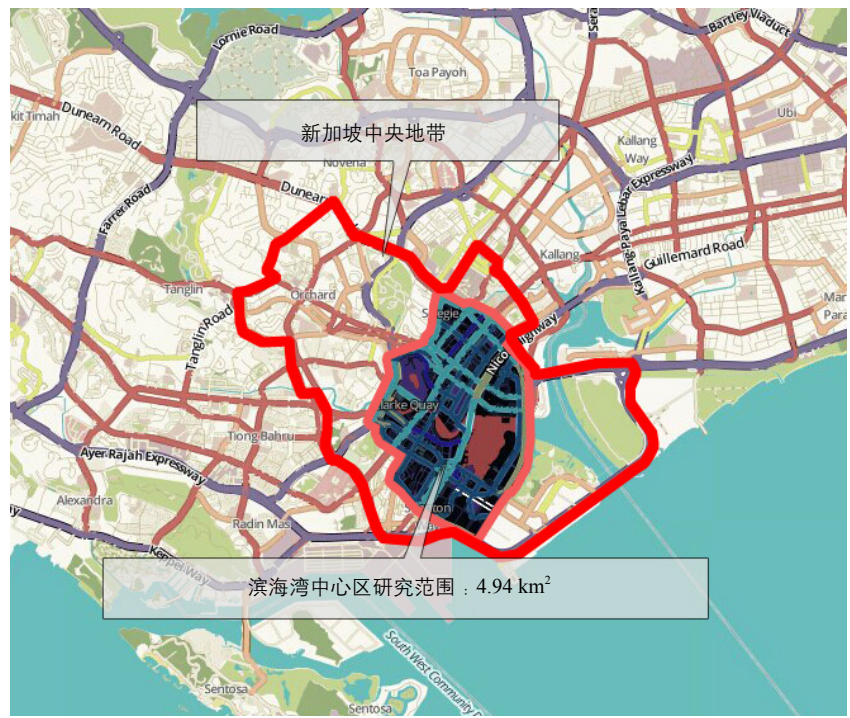

图 1 滨海湾中心区区位与研究范围

资料来源 : 作者绘制, 底图来自 Openstreetmap. http://www.openstreetmap.org/

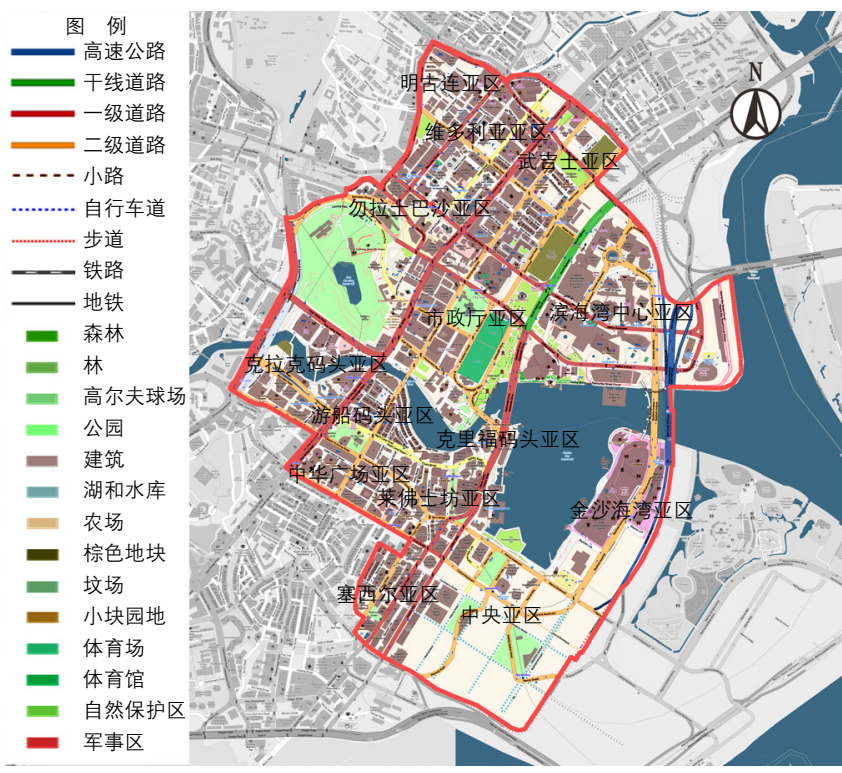

图 2 滨海湾中心区总平面图

资料来源 : 作者绘制，底图来自 Openstreetmap. http://www.openstreetmap.org/.
城市是多尺度转换的体系, 笔者认为, 基于多尺度的分 析，更易于理解从 “人的尺度” 到 “城市尺度” 的城市空间 与功能关系, 从而深人探讨功能与空间模式的本质, 因此本 研究从大、中、小三个尺度进行剖析, 以解读滨海湾的总体 功能结构与街区业态之间的相互关系。

\section{2 滨海湾区的城市结构}

\section{1 滨海湾区的亚区与中央景观基础设施结构}

总体结构是城市功能分配的框架, 也是城市规划中最早 划定的城市 “模板”, 这一模板会自上而下影响中小尺度功 能混合的建立 (图 2)。

滨海湾区的在总体结构上以滨海湾湖与新加坡河 (Singapore River) 为主要生态骨架, 依据地理环境特征由 北至南成团状展开, 构成以一湖（滨海湾湖）、一河（新加 坡河）、一公园（福康宁公园 [Fort Cannin Park]）为核心的 “中央景观基础设施”, 以及周边 14 个亚区环绕组合的结 构（图 3)。亚区包括：金沙海湾亚区（Bayfront Subzone）、 中央亚区（Central Subzone）、塞西尔亚区（Cecil）、滨海湾 中心亚区 (Marina Centre)、市政厅亚区 (City Hall)、克里 福码头亚区 (Clifford Pier)、游船码头亚区 (Boat Quay)、 克拉克码头亚区 (Clarke Quay)、勿拉士巴沙亚区 (Bras asah)、武吉士亚区 (Bugis)、明古连亚区 (Bencoolen)、维 多利亚亚区（Victoria）、中华广场亚区（China Square）和莱 佛士坊亚区（Raffles Place） ${ }^{[7]}$ 。高密度亚区与开敞的中央景

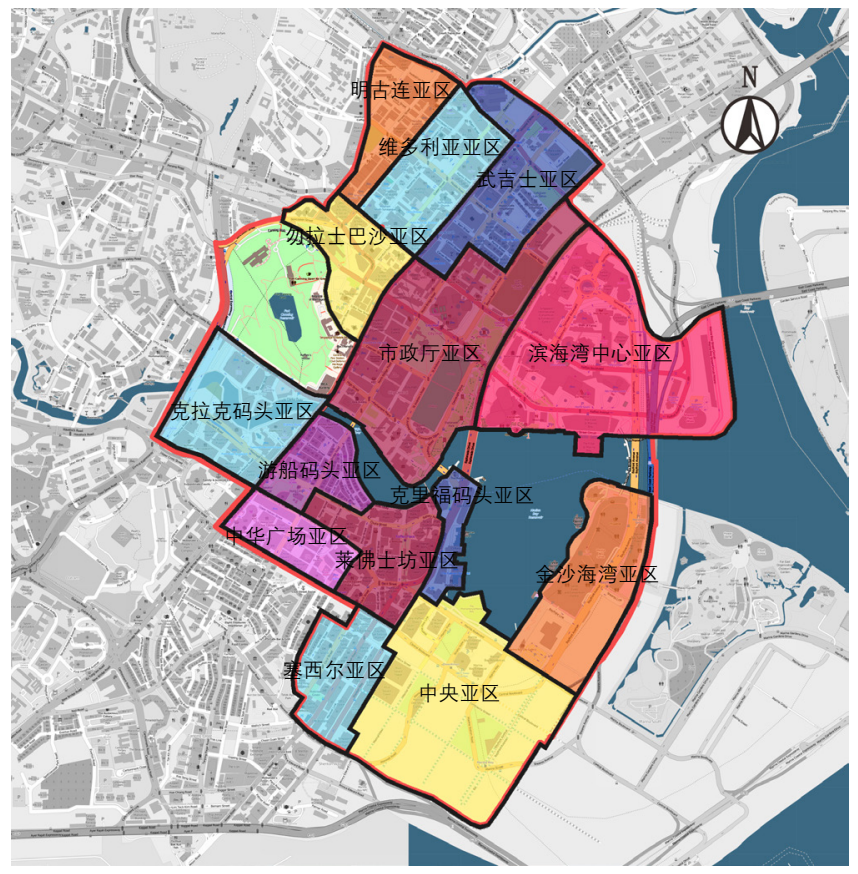

图 3 滨海湾中心区亚区分区

资料来源 : 作者绘制, 底图来自 Openstreetmap. http://www.openstreetmap.org/. 
观基础设施区域能有效地形成对应关系, 在功能与形态上均 形成良好的互补, 为滨海湾整体功能的协调发展提供良好的 生态与结构基础。

滨海湾核心组团的中央景观基础设施是一个由自然景观 水面与公园绿地混合构筑的中心景观区域, 为滨海湾的城市 系统提供了一个稳固的基底, 这种方法并非把景观等同于自 然或生态环境, 如此一来, 就可以有更具操作性的概念框架 来设计城市系统与城市活动。

滨海湾的特色区域划分单元一一亚区则被认为是新加坡 政府对城市空间与功能细分进行差异化定制的限定性框架, 亚区的划定可以使项目的进驻更为灵活, 大大地降低地块的 同质性, 形成丰富多样的场地体验。

\section{2 滨海湾区亚区特征}

亚区的概念并非新加坡首次提出, 伦敦在中央活动区 (CAZ: Central Activities Zone) 的规划设计中, 也提出了类 似概念 (Subarea) ${ }^{[8,9]}$ 。倘若以新加坡的亚区对比伦敦 CAZ 的 Subarea 和现代主义功能分区, 可发现滨海湾的亚区呈现 出以下特征。

(1) 亚区单元面积较小

滨海湾亚区的平均大小为 $0.3 \mathrm{~km}^{2}$ 左右, 超过 $0.5 \mathrm{~km}^{2}$ 的 已属于大型亚区, 其中最大的滨海湾中心亚区为 $0.71 \mathrm{~km}^{2}$, 最小的克里福码头亚区仅为 $0.08 \mathrm{~km}^{2}$, 相差较大, 相比伦敦 CAZ 的 Subarea 平均 $0.5 \mathrm{~km}^{2}$ 的规模和国内深受现代主义影 响的深圳福田中心区 $2 \mathrm{~km}^{2}$ 的功能区, 新加坡的亚区规模明 显较小, 其尺度甚至小于传统村落（表 1)。

(2) 亚区数量多

由于亚区规模较小, 因此其数量有所增加, 整个核心地 区可被划分为更为细密的亚区单元。

(3) 中小亚区居多

在亚区大小配置上, 滨海湾的亚区以 $0.2 \sim 0.3 \mathrm{~km}^{2}$ 的居 多, 而超过 $0.5 \mathrm{~km}^{2}$ 的 “大” 亚区较少, 形成金字塔式的分

\section{表 1 滨海湾亚区面积对比表}

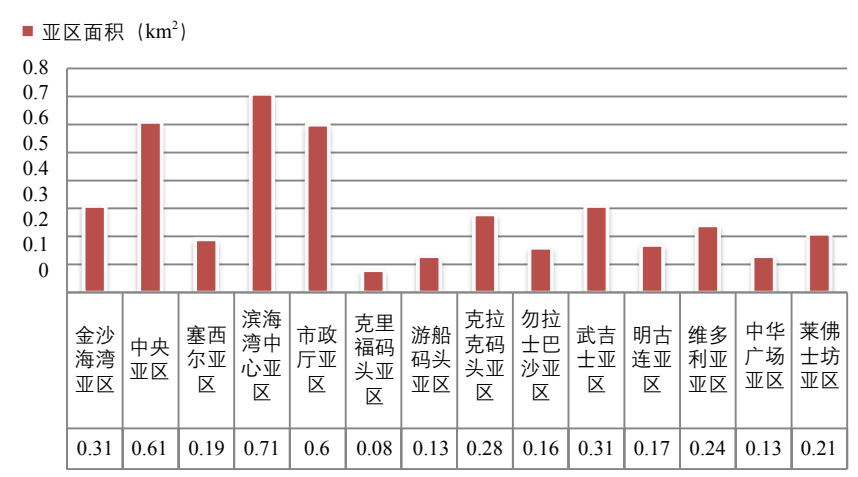

资料来源 : 根据参考文献 [7] 整理
布。这一结构形成的主原因在于滨海湾是由历史城区发展 而成的, 同功能性质的区域一般较小, 新拓展的城区在街 区大小上也一直致力于与原来的老城市肌理相衔接, 并且 为了使得规划操作更具灵活性, 新区域格网肌理规划还划 分了多个可融合和分割的小型地块以及数个大型地块以方 便滨海湾地区容纳大型建筑, 因此亚区单元大多面积不大, 发展较为紧凑。

\section{3 滨海湾区亚区的作用与意义}

滨海湾区 “小型” 亚区的主要作用是为中心区划定数量 更多的 “小单元” 骨架。所谓城市单元, 应该是指具有异质 性形态或者功能的具体控制手段, 而不是同质项目的划分手 段。我国许多遵循现代主义模式构建的事实上是 “大单元” 结构, 其中最大的问题在于没有通过提高功能的复杂性来有 效培育城市空间的多样性，大单元使得本该有的城市 “异质 性单元” 大大减少了, 这样的城市设计一开始就丧失了中小 尺度生成多样性结构的基础。

滨海湾 “中小亚区多, 大亚区少” 的单元体系, 有利于 为中心区划分出更加多样的功能单元, 是保证整个区域建构 多样混合功能的基础架构, 可以有效避免大功能区开发带来 的中心区同质化现象。大小不一的亚区能构建更为多样、细 密的城市纹理结构, 为中小尺度混合功能的细化提供载体。 在后续管理上, 亚区更是新加坡政府监控和管理滨海湾地区 开发运作的重要单元。政府通过规划管理引进功能各异的项 目, 并依据项目大小分配进亚区, 从而保证各个亚区的公共 空间质量与业态的混合。

\section{3 滨海湾区的混合功能配置}

构建了合理的亚区骨架之后, 首要问题是如何在此结构 之下分配土地功能, 同时引进适宜的项目。混合功能是新加 坡政府对地区土地使用首要强调的准则 ${ }^{[10]}$, 但面对 14 个亚 区, 如果功能均匀配置必然会造成中心不突出、特色混乱, 最终导致中心区的特色与活力丧失, 因此有侧重的分配是土 地健康混合的关键。

\section{1 混合使用的特点}

混合使用的概念一般与高强度的土地利用和多元的使用 性质相关。混合使用具有以下特点 :

- 三种或三种以上、能够吸引人流和产生税收的土地利用;

- 这些土地利用之间相互包容;

- 在一定的地理范围内形成平衡 ;

- 在空间环境和服务功能上相互协作, 产生协调和聚集 效应 ${ }^{[11]}$ 。 
雅各布斯也曾对土地混合使用的基础做过划分，分为 “主要土地利用”和“次要土地利用”。“主要土地利用”主 要指居住用地和那些能够提供就业的功能用地, 包括办公用 地、工业用地、重要娱乐休闲设施和教育用地, 能够吸引人 们来到特定场所, 并促进对次要土地使用的需求。“次要土 地利用”则包括居住、酒店、餐厅、酒吧等用地, 是那些在 主要土地利用繁荣后引发的附属使用土地, 而这些用地在达 到一定的发展程度后也可能提升转化为主要土地利用。这 两种土地使用的互动保证了城市场所的活力、吸引力和安 全性 ${ }^{[11]}$ 。本文主要以雅各布斯的土地分类为基础探讨滨海湾 区的土地利用混合, 但考虑到滨海湾的中心性特征, 将居住 用地归类为次要土地利用范畴。

\section{2 滨海湾区基于亚区的混合功能配置}

作为新加坡的中心地带, 滨海湾区在功能上主要体现出 5 种主要土地利用功能 : 商业、商务、休闲娱乐、行政和文 化艺术。这 5 大类功能需要分配至 14 个亚区单元, 加上酒店、 餐饮、零售、文化娱乐等支撑性次要土地利用功能, 在功能 混合的分配上应有侧重（图 4)。

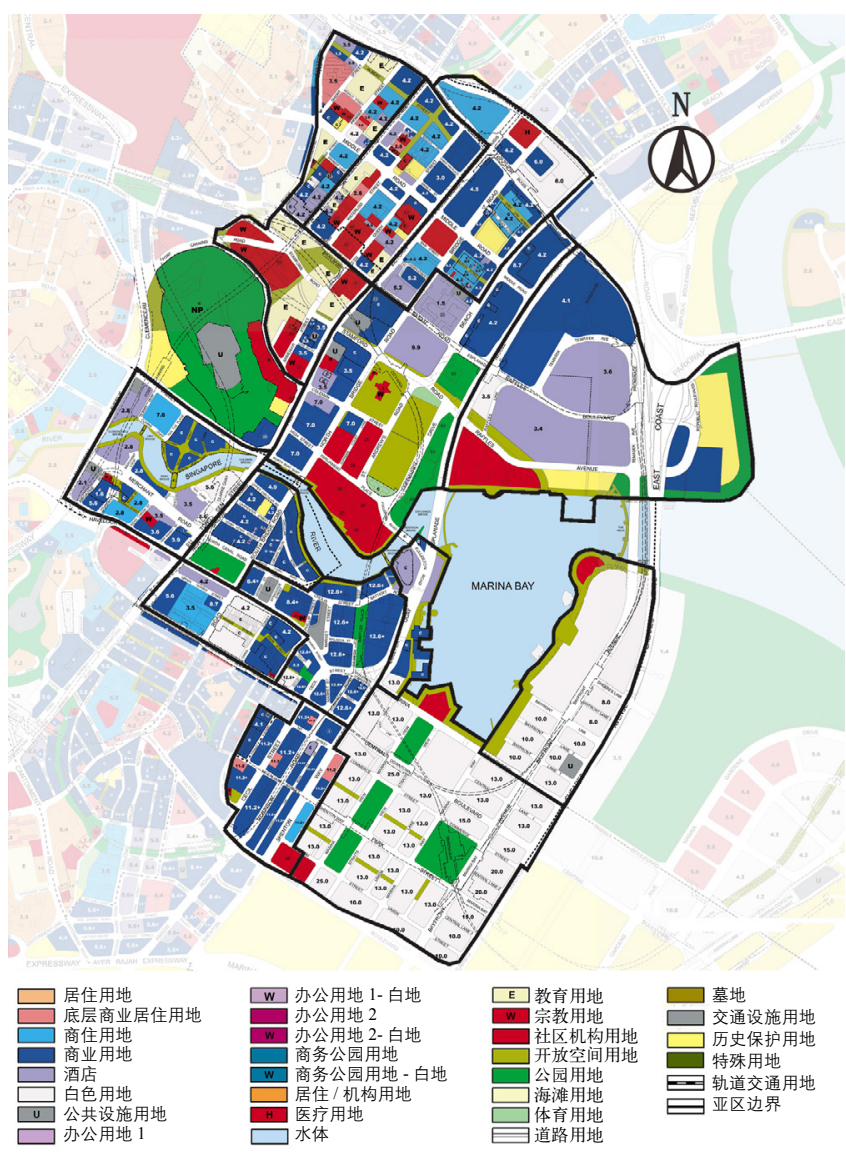

图 4 滨海湾中心区 2014 年土地利用与容积率规划 资料来源 : 根据参考文献 [7] 改绘

\subsection{1 功能分配一一主、次亚区分化发展}

滨海湾区功能上形成的分配模式是 “主、次亚区分化发 展”, 即亚区针对一种主要土地利用功能一般会分化为 2 个 甚至 3 个亚区, 而不是如现代主义的功能分区模式形成 “一 对一” 的巨大功能单元。其中, 主亚区承担中心区的一个主 要土地利用功能, 以保持功能的中心性; 而次亚区则分担副 中心功能以形成一主一次的相互结合, 如莱佛士坊主亚区与 塞西尔次亚区。

从功能类型看, 滨海湾区可划分为 5 个以 “主要土地利 用” 为主体的 “主亚区”, 9 个以 “次要土地利用” 为主体 的“次亚区”（表 2)。主亚区与次亚区均具有混合功能的特 性, 而非单一的功能区域。两者的区别在于, 主亚区的某主 要土地利用功能比例较高, 混合的功能仍以其他主功能为主, 如娱乐、商业购物; 而次亚区的主要土地利用功能比例较低, 可能会结合两种比例接近的主功能, 而混合的功能则主要以 次要土地利用功能居多, 如居住、酒店等, 例如武吉士亚区 和明古连亚区。部分次亚区以次功能为主体, 如维多利亚与 勿拉士巴沙亚区以及游船码头亚区。

\section{表 2 滨海湾区亚区功能对比表}

\begin{tabular}{|c|c|c|c|c|c|}
\hline & 名称 & 功能类型 & 主要功能 & 次要功能 & 日常服务功能 \\
\hline \multirow{5}{*}{$\begin{array}{l}\text { 主 } \\
\text { 亚 } \\
\text { 区 }\end{array}$} & 金沙海湾亚区 & $\begin{array}{l}\text { 娱乐综合主 } \\
\text { 亚区 }\end{array}$ & 商业、酒店 & $\begin{array}{l}\text { 旅游、文化 } \\
\text { 娱乐 }\end{array}$ & 餐饮 \\
\hline & 莱佛士坊亚区 & $\begin{array}{l}\text { 金融商务主 } \\
\text { 亚区 }\end{array}$ & $\begin{array}{l}\text { 金融、商务 } \\
\text { 办公 }\end{array}$ & 商业 & 零售 \\
\hline & 中央区 & $\begin{array}{l}\text { 商务综合主 } \\
\text { 亚区 }\end{array}$ & $\begin{array}{l}\text { 商务办公、 } \\
\text { 金融 }\end{array}$ & $\begin{array}{l}\text { 文化娱乐、 } \\
\text { 酒店、商业 }\end{array}$ & $\begin{array}{l}\text { 餐饮、零售、 } \\
\text { 休闲娱乐 }\end{array}$ \\
\hline & 滨海中心亚区 & 娱乐主亚区 & 演艺 & $\begin{array}{l}\text { 商业、旅游、 } \\
\text { 文化娱乐 }\end{array}$ & 餐饮 \\
\hline & 市政厅亚区 & 行政主亚区 & 行政办公 & $\begin{array}{l}\text { 旅游、商业、 } \\
\text { 体育 }\end{array}$ & 餐饮 \\
\hline \multirow{9}{*}{$\begin{array}{l}\text { 次 } \\
\text { 亚 } \\
\text { 区 }\end{array}$} & 塞西尔亚区 & 商务次亚区 & 商务办公 & 商业、酒店 & 餐饮 \\
\hline & 克里福码头亚区 & 酒店次亚区 & 酒店、商业 & $\begin{array}{l}\text { 旅游、文化 } \\
\text { 娱乐、 }\end{array}$ & 餐饮、零售 \\
\hline & 游船码头亚区 & $\begin{array}{l}\text { 休闲娱乐次 } \\
\text { 亚区 }\end{array}$ & 文化娱乐 & 旅游、商业 & 餐饮、零售 \\
\hline & 克拉克码头亚区 & $\begin{array}{l}\text { 商业娱乐次 } \\
\text { 亚区 }\end{array}$ & 商业、娱乐 & 旅游 & 餐饮、零售 \\
\hline & 勿拉士巴沙亚区 & 居住次亚区 & 居住、酒店 & 文化娱乐 & 餐饮 \\
\hline & 武吉士亚区 & 商业次亚区 & 商业、旅游 & $\begin{array}{l}\text { 宗教、居住、 } \\
\text { 酒店 }\end{array}$ & $\begin{array}{l}\text { 餐饮、零售、 } \\
\text { 休闲娱乐 }\end{array}$ \\
\hline & 明古连亚区 & 商住次亚区 & 商业、居住 & $\begin{array}{l}\text { 酒店、教育、 } \\
\text { 宗教 }\end{array}$ & 零售、餐饮 \\
\hline & 维多利亚亚区 & 商住次亚区 & 居住、办公 & 商业、宗教 & 餐饮、零售 \\
\hline & 中华广场亚区 & 商业次亚区 & 商业、办公 & 酒店 & $\begin{array}{l}\text { 休闲娱乐、餐 } \\
\text { 饮 }\end{array}$ \\
\hline
\end{tabular}

资料来源：根据参考文献 [7] 和笔者调研资料整理 


\subsection{2 布局模式一一主、次亚区粘连、交错布置}

在亚区的空间组合上, 主次亚区应该粘连发展, 以分享 承担集聚效应, 如莱佛士坊与塞西尔。由于主、次亚区粘连 结合可以使得功能的中心性得到进一步凸显, 同时次亚区大 量的零售、酒店、旅游等支撑性功能能满足主亚区对功能的 混合需求, 并保持次亚区独有的特色与吸引力。

另外, 其他支撑性功能为主的次亚区主要围绕主亚区 进行布置, 形成 “主次交错” 的格局, 以在主亚区较小的步 行距离内体验更加多元化的功能, 形成丰富多样的城市体验 (图 5)。

\subsection{3 日常服务功能混合一一全亚区配置}

滨海湾所有的亚区均配置有日常服务性的功能, 如餐饮、 休闲、零售等。由于主亚区地面层价格高昂, 因此日常服务 性的功能常与地铁站相结合 ${ }^{[12]}$, 或分布于地面小尺度街区空 间, 甚至成为亚区的主要功能, 如游船码头和克拉克码头亚区。

\subsection{4 小结}

总体来说, 滨海湾亚区的功能组合模式特征可以归纳为 以下几种 :

- 中心区的主要土地利用功能可依据亚区拆分, 主、次 结合;

- 相关联的主要土地利用功能与次要土地利用功能在 主、次亚区中相互混合配置, 主亚区主功能比例高, 次亚区 则相对均衡 ;

- 全亚区均需配置日常服务性功能;

- 相同功能的主、次亚区组合粘连结合;

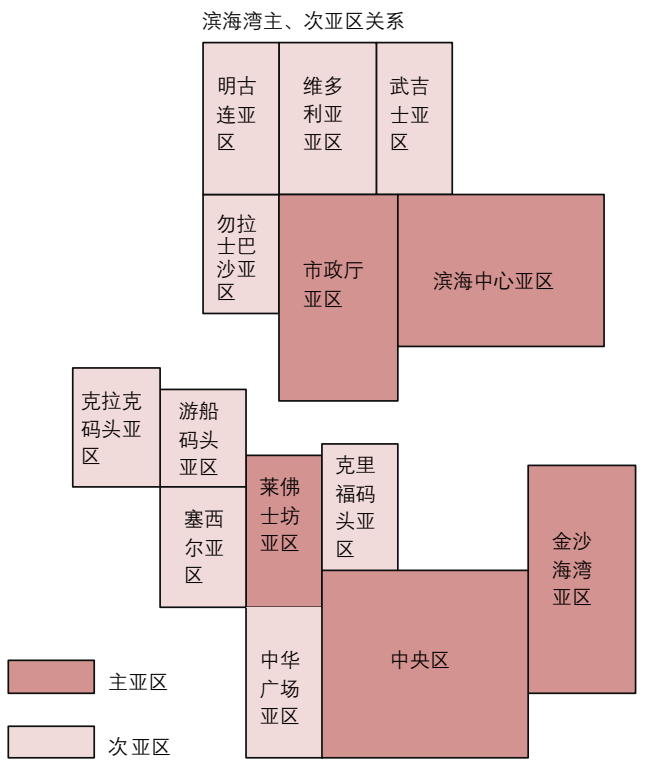

图 5 滨海湾区主、次亚区关系与亚区土地功能配置对比图
- 配置次要土地功能的次亚区围绕主亚区交错布置, 形 成良好支撑。

\section{4 滨海湾区多样尺度城市空间与功能的组合}

\section{1 混合功能、密度与尺度的相互关系}

将城市肌理作为一个不可分割的物质和社会复合体进行 研究将是城市研究的重要阶段, 把所有观察资料综合起来可 发展成为真正的城市系统 ${ }^{[13]}$ 。这个系统中, 依靠 “密度” 实 现城市混合性的准则已广为规划者所知, 功能混合也需要充 分的人口密度的集聚, 才能支持地方的活力, 一定的肌理密 度是混合使用的必要条件 ${ }^{[11]}$ 。

从滨海湾区的城市肌理上看, 由于小型亚区单元肌理紧 凑的特点, 其街区尺度多维持在 100 200 m 之间, 建筑密度 较高, 并随着滨海湾湖与绿地开放空间有机分布, 具有良好 的容纳城市活力的空间。

除了密度之外, 另一项影响城市混合性功能的重要因素 是尺度, 即城市元素的规模大小。事实上, 不同的城市主、 次功能需要不同规模的建筑载体, 比如大型商务办公需要密 集型的大型高层建筑, 而小型的零售业与餐饮业则需要较小 的建筑门面或者街道, 这些属性是构建城市多样混合性的基 础，但在当代中心区规划中往往被忽略。

\section{2 现代主义中心区模式的尺度缺失问题}

许多参照柯布西耶 “现代主义” 手法产生的中心区缺乏 人性的主要原因在于城市空间尺度连续性的缺乏, 其中显著 的特点在于小尺度空间的严重缺失。

当代中国许多中心区的设计模式受现代主义建筑学影

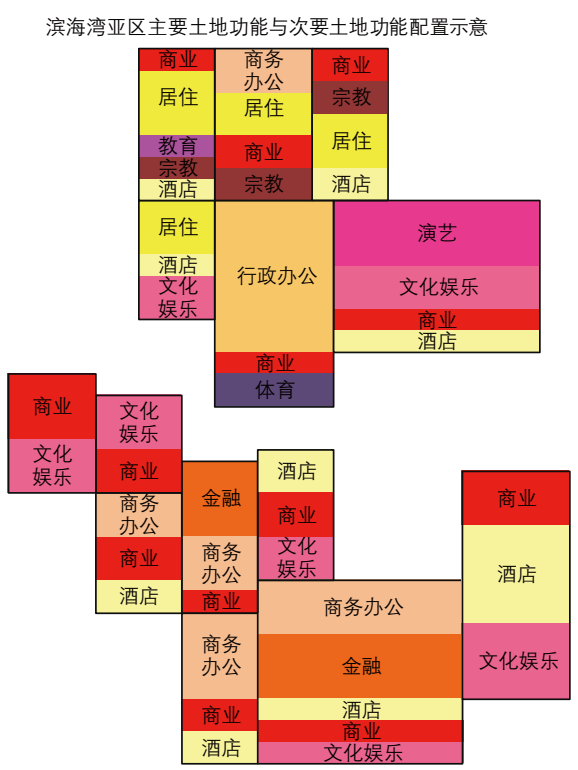


响, 偏好组合同尺寸、同质性的元素, 例如并列的塔楼和 大型公共建筑, 却很少承认城市作为复杂性载体所承担的 多尺度特征, 而小型甚至中型尺度的元素在 CBD 中常被视 为异类而除之后快, 并冠之以 “紧凑发展” 的理由。尼科 斯·A · 萨林加罗斯（Nikos A. Salingaros）通过对城市复杂 性的研究, 指出人类对人性化环境的认同是由连续的尺度实 现的, 连续的尺度层级是形成城市多样化和富有魅力的环 境的基础 ${ }^{[14]}$ 。因此一个健康、拥有多样活力与丰富体验的 城市首先应具备中和 “人类尺度”与 “城市尺度” 的能力。

\section{3 滨海湾区多样的城市尺度组合策略}

滨海湾区在城市尺度上具有一个人一城尺度的连续转换 体系, 这一体系是基于中心区域一亚区一街区这样的尺度骨 架构建而成的。

\subsection{1 总体尺度一一容积率组团状布置}

容积率是建筑坚向尺度的抽象体现。从滨海湾区的总体 形态上看, 主、次亚区的结合不仅是功能混合性上的结合, 也表现在建筑容积率的不同。高容积亚区与中、低容积亚区 间隔分布, 使整个区域密度呈有机团状分布, 呈现出南面高 容积、中部中容积、北面低容积的特点（图 5)。最高的容 积率基本分布在金沙海湾、中央区、塞西尔 3 个亚区, 形成 3 个高密度团状区域, 地块的容积率多在 10 以上; 中部的市 政厅亚区属于中等容积区域, 地块容积率 3.5 9.9; 北部、西 部以及东部外围亚区容积率相对较低, 但仍较紧凑, 地块容
积率控制在 3.5 5 之间。容积率最高的是中央区, 容积率为 13 25; 容积率最低的是克拉克码头亚区, 容积率 2 3; 其他 地区容积率多分布在 4 6 之间（图 6)。高容积率的商务区一 般围绕滨海湾湖 “单面发展”。

\subsection{2 亚区尺度一一高容积街区与低容积街区结合}

总体容积率的特点在亚区体现为亚区建筑尺度的差异, 这一差异与街区大小结合, 控制着城市空间变换的体验。滨 海湾地区的多样性正是根植于亚区不同的街区尺度与建筑特 征的组合 (表 3), 这些组合与亚区的业态紧密联系形成了连 续而丰富的城市中心区体验。

以莱佛士坊亚区及其周边为例, 莱佛士坊亚区作为传统 $\mathrm{CBD}$, 是大尺度的摩天塔楼与裙楼的结合, 与其紧邻的游船 码头亚区则是典型的低密度传统街道区域（图 7)。若以现 代主义的 CBD 标准来衡量, 游船码头与莱佛士坊这样大小 悬殊的组合是极不协调的, 因为它们背离了现代主义建筑的 美学标准。但真实的使用状况是, 无论成因如何, 两者的组 合非常符合城市的复杂性特性和人们对空间多样性体验的需 求。首先, 游船码头亚区内多为低密度的紧凑街道, 街道宽 度多在 5 10 $\mathrm{m}$ 之间, 楼层高度约为 3 4 层, 属于传统的小 型城市街道, 因此在功能上有利于容纳餐饮、零售、娱乐等 生活休闲性产业, 可以很好地为莱佛士坊亚区提供丰富的功 能混合体验。其次, 尽管莱佛士坊亚区内部也布置了零售与 地下餐饮业务, 但游船码头的小街道所提供的独特体验是高 容积地区无法比拟的。因此, 从新加坡河一游船码头一莱佛

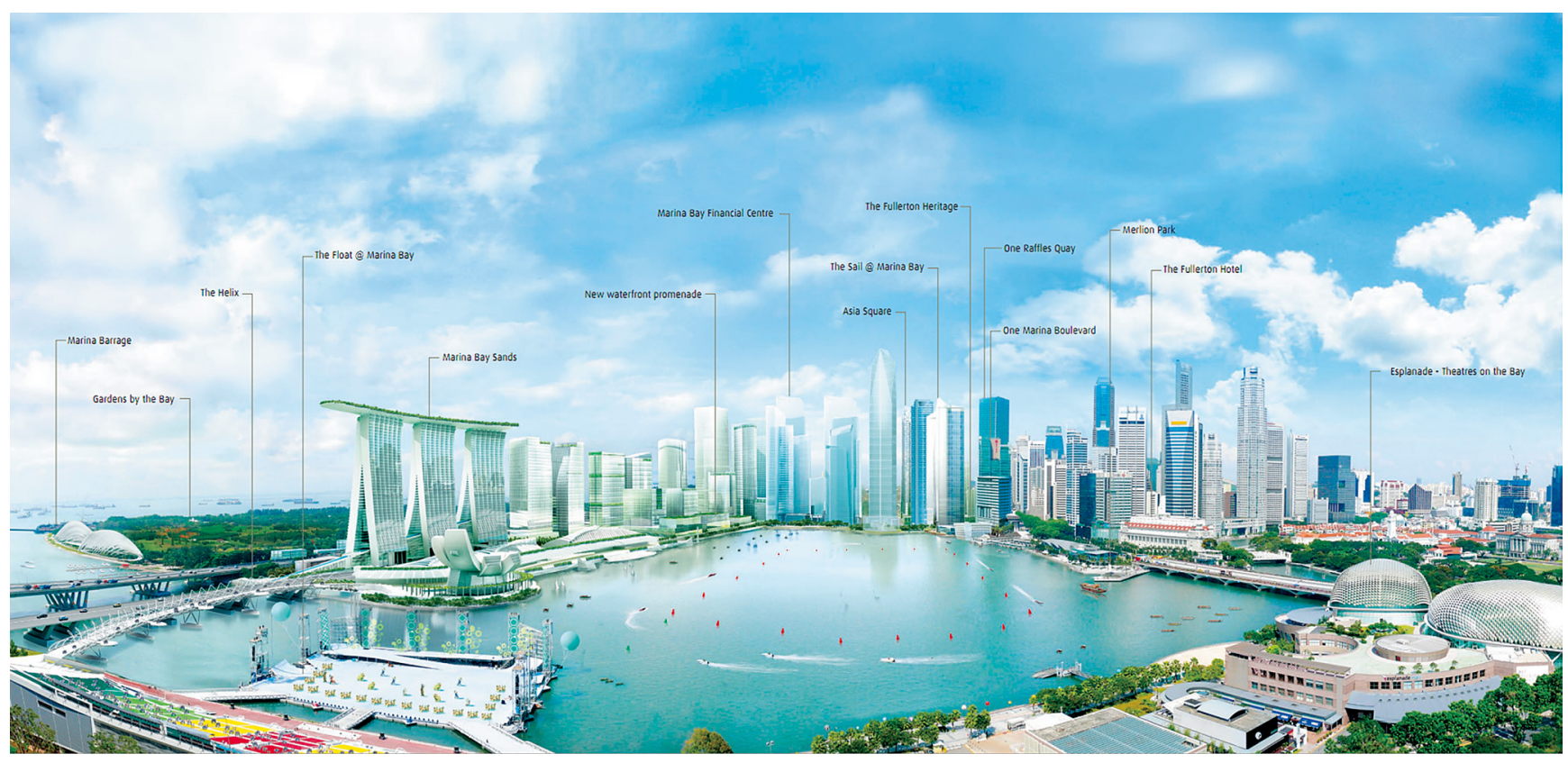

图 6 滨海湾中心区乌瞰 资料来源 : 参考文献 [5] 
土坊, 短短 $500 \mathrm{~m}$ 范围内形成了多样的空间与业态体验, 结 合中小尺度的克里福码头与对岸的市政厅亚区, 新加坡河沿 岸有着尺度宜人、丰富多样的空间与业态, 这样的组合也正 是滨海湾区充满多样魅力的重要原因。

\subsection{3 街区尺度一一小型空间作为地面的基底优先发展}

当下国内许多 CBD 不够人性化的一个重要原因是缺乏 容纳小型业态的建筑和空间, 其根源在于其临摹的蓝本仍是 柯布西耶式的中心区模式。在这一模式中, 大尺度的建筑在 城市中必须占据主导地位, 而本该作为优先级的大量中小尺 度空间缺失。这些建筑既不具备人性尺度, 也没有中和从人 性尺度至大型尺度的中间尺度, 因此许多小型日常生活业态 如餐饮和休闲难以在城市中找到相应的载体, 在功能混合性 上也会大打折扣。

与现代主义模式相反, 滨海湾区实施的城市设计策略优 先考虑了连续的中小尺度环境, 其措施包括 :

- 在历史性区域更新中保存大量的中、小尺度街区 ;

- 利用城市设计引导、规定高层建筑的退台式裙房以及 连续的骑楼连接大量的公共空间 ${ }^{[10,16]}$, 保证连续的小尺度步 行体验;

- 结合 TOD 模式, 利用地铁空间与综合体增加小尺度 业态空间, 使其为亚区提供更好的混合功能服务。

\section{5 滨海湾区城市混合功能与尺度关系模式总结}

从新加坡滨海湾区的建设可以看到, 作为一个被公认的 高紧凑性地区, 其所谓的 “紧凑性” 并非大面积的高容积率 铺设, 而是根据城市历史、地理特点在亚区中呈团状分配。 因此在许多高容积的 “主亚区” 边上常粘连着中容积甚至低

\section{表 3 滨海湾区亚区街区尺度类型与特征对比表}

\begin{tabular}{|c|c|c|c|}
\hline & 名称 & 街区主要尺度类型 & 特征描述 \\
\hline \multirow{5}{*}{$\begin{array}{l}\text { 主 } \\
\text { 亚 } \\
\text { 区 }\end{array}$} & 金沙海湾亚区 & 高密度、高容积率 & 大型建筑综合体 \\
\hline & 莱佛士坊亚区 & 高密度、高容积率 & 塔楼和裙楼 \\
\hline & 中央区 & 高密度、高容积率 & 塔楼、裙楼和大型综合体 \\
\hline & 滨海中心亚区 & 高密度、中容积率 & 大型综合体和大型演艺场所 \\
\hline & 市政厅亚区 & 中密度、中容积率 & 独立大型公建和紧凑办公区 \\
\hline \multirow{9}{*}{$\begin{array}{l}\text { 次 } \\
\text { 亚 } \\
\text { 区 }\end{array}$} & 塞西尔亚区 & 高密度、中、高容积率 & 高层、部分塔楼和裙楼 \\
\hline & 克里福码头亚区 & 高密度、低容积率 & 多层建筑 \\
\hline & 游船码头亚区 & 高密度、低容积率 & 传统小街区 \\
\hline & 克拉克码头亚区 & 高密度、低容积率 & 传统小街区 \\
\hline & 勿拉士巴沙亚区 & 中密度、中容积率 & 邻里式街区 \\
\hline & 武吉士亚区 & 高密度、中容积率 & 综合体和邻里式街区 \\
\hline & 明古连亚区 & 中密度、中容积率 & 邻里式街区 \\
\hline & 维多利亚亚区 & 中密度、中容积率 & 邻里式街区 \\
\hline & 中华广场亚区 & 高密度、中容积率 & 综合体 \\
\hline
\end{tabular}

容积的 “次亚区”, 这样的结构不仅保证了大小空间的均质 分布, 还提供了零售、餐饮等小型业态集聚的场所, 从而创 造出功能与空间的多样化体验。因此滨海湾的功能混合与城 市设计尺度之间是一个相呼应的整体, 其在不同尺度的策略 可总结如下 (表 4)。

\section{6 小结与展望}

对结构与基础模式的把控是城市设计 “自上而下” 发展 的重要手段, 错误的模式与结构会抑制“自下而上”多样性 的产生。从滨海湾的功能混合与空间组合模式可以看到, 多 样性魅力的产生并非如表面所见那样仅源于良好的建筑设 计, 更重要的是对城市肌理与结构复杂性内部规律的把控与 创造。

回顾中国当下的中心区建设，尽管包装了许多可持续性 的理念, 但实践模式还是源于对柯布西耶 “光辉城市” 的变 形, 其同质化元素的构建方法如并置的连续大型场馆、庞大 而孤立的塔楼式 CBD 在功能与尺度上违背了城市复杂性的

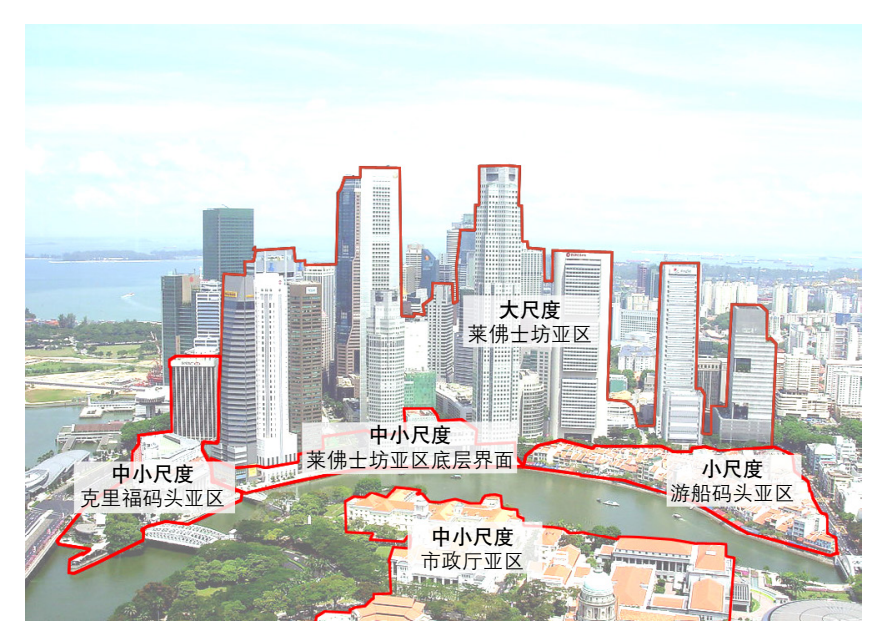

图 7 莱佛士坊亚区与周边亚区尺度关系

资料来源 : 根据参考文献 [15] 改绘

\section{表 4 滨海湾混合功能与尺度关系策略关系模式表}

\begin{tabular}{|c|c|c|c|}
\hline & 总体层面 & 亚区层面 & 街区层面 \\
\hline $\begin{array}{l}\text { 混 } \\
\text { 合 }\end{array}$ & $\begin{array}{l}\text { 商业中心 + 商务中 } \\
\text { 心 + 休闲娱乐中心 } \\
+ \text { +行政中心 + 文化 } \\
\text { 艺术中心 }\end{array}$ & $\begin{array}{l}\text { 1) 主亚区 }+ \text { 次亚区; } 2) \\
\text { 主亚区: } 1 \text { 种主土地功能 } \\
+2 ~ 3 \text { 种主土地功能或数 } \\
\text { 种次土地功能; } 3) \text { 次亚 } \\
\text { 区 : 2 3 种主土地功能 }+ \\
\text { 数种次土地功能 ; 4) 全 } \\
\text { 亚区配置日常服务性功 } \\
\text { 能 }\end{array}$ & $\begin{array}{l}\text { 1) 平面: 利用小街区提 } \\
\text { 供餐饮与娱乐休闲功能混 } \\
\text { 合；2）坚向：利用地铁 } \\
\text { 地下空间与摩天楼底层提 } \\
\text { 供餐饮与娱乐休闲功能混 } \\
\text { 合; 3) 综合 : 利用综合 } \\
\text { 体提供零售、餐饮与娱乐 } \\
\text { 休闲功能混合 }\end{array}$ \\
\hline $\begin{array}{l}\text { 城 } \\
\text { 市 } \\
\text { 尺 }\end{array}$ & $\begin{array}{l}\text { 1) 中央景观基础 } \\
\text { 设 施 +亚区; 2) } \\
\text { 容积率根据亚区围 } \\
\text { 绕中央公 园 “团 } \\
\text { 状” 分布 }\end{array}$ & $\begin{array}{l}\text { 1）高容积亚区 }+ \text { 低容积 } \\
\text { 亚区；2）小尺度街区； } \\
\text { 3）紧凑肌理 }\end{array}$ & $\begin{array}{l}\text { 1) 大尺度塔楼群 +中. } \\
\text { 小尺度街区；2）地面有 } \\
\text { 大量、连续的中小尺度空 } \\
\text { 间；3）塔楼群 + 裙楼 }+ \\
\text { 骑楼连廊 }\end{array}$ \\
\hline
\end{tabular}


规律, 造成了尺度的断裂和小型业态空间的缺失, 因此会形 成单调、乏味的城市空间体验。

滨海湾地区作为传统历史城市向现代国际大都市发展的 区域, 其中许多小尺度空间是依赖于历史区域生长起来的, 这种多尺度空间结合的现状模式可作为中心区的成熟样本被 正视，并应用到中国当代的中心区建设中，通过多样的空间 载体激发多样的混合功能。 UPI

注：文中未注明来源的图表均为作者自绘。

\section{参考文献}

[1] 袁琳. 城市史视野下新加坡 “田园城市” 的再认识及启示 [J]. 风景园 林, 2010(6): 107-112.

[2] 杨沛儒. 城市核心区设计：新加坡的亚洲经验 [J]. 城市规划, 2005(3): $55-61$.

[3] 楚天骄. 城市转型中新加坡 CBD 的演化及其启示 [J]. 现代城市研究, 2011(10): 35-41.

[4] Marina Bay Brochure[R]. Urban Redevelopment Authority, 2011.

[5] Marina Bay Singapore[R]. Urban Redevelopment Authority, 2010.

[6] The Singapore Advantage Brochure[R]. Urban Redevelopment Authority, 2010.

[7] Singapore Master Plan 2014[R]. Urban Redevelopment Authority, 2014.

[8] CAZ Planning \& Transportation Supplementary Planning Guidance[R]. London: Westminster City Council, 2001.

[9] 张庭伟, 王兰.从 CBD 到 CAZ : 城市多元经济发展的空间需求与规 划 [M]. 中国建筑工业出版社, 2011 .

[10] 郭素君, 姜球林. 城市公共设施空间布局规划的理念与方法——新加 坡经验及深圳市光明新区的实践 [J]. 规划师, 2010(4): 5-11.

[11] Jacobs Jane. The Death and Life of Great American Cities[M]. Vintage, 1992.

[12] 张琦. 新加坡地铁站体的综合开发 [J]. 城市轨道交通研究, 2008(2): 65-67.

[13] Serge Salat. Cities and Forms: On Sustainable Urbanism[M]. Herman, 2011.

[14] Salingaros N A. Principles of Urban Structure[M]. Amsterdam: Techne Press, 2005.

[15] 昵图网. 新加坡旅游摄影 [DB/OL]. (2009-03-03)[2015-03-15]. http:// www.nipic.com/show/1/73/3401dd1ae72c5b78.html.

[16] 王才强, 刘文良. 多层次构成的新加坡公共空间 [J]. 新建筑, 2012(5): 4-9.

(本文编辑：张祎娴) 